\title{
A INTEGRAÇÃO DA NOÇÃO DE SOBERANIA NA CONCEPÇÃO PREDOMINANTE DE SEGURANÇA ALIMENTAR E NUTRICIONAL NO BRASIL
}

\author{
Paulo Eduardo Moruzzi Marques ${ }^{1}$ \\ iD https://orcid.org/0000-0002-0514-7568 \\ Natália Gebrim Doria ${ }^{2}$ \\ iD https://orcid.org/0000-0003-4076-2918
}

\begin{abstract}
RESUMO
O artigo apresenta uma interpretação sobre a evolução do debate em torno da noção de segurança alimentar e nutricional no Brasil. As ambiguidades que caracterizam as conceituações de segurança alimentar são tomadas como ponto de partida para explicar a emergência da noção de soberania alimentar. No caso brasileiro, a integração desta última na construção de sentidos de segurança alimentar e nutricional marca as reivindicações do movimento social e as iniciativas públicas neste âmbito.
\end{abstract}

Palavras-chave: Segurança Alimentar, Soberania Alimentar, Políticas Públicas Agroalimentares, Agricultura Familiar, Direito Humano à Alimentação Saudável.

\section{THE INTEGRATION OF THE NOTION OF SOVEREIGNTY IN THE PREDOMINANT CONCEPTION OF FOOD AND NUTRITIONAL SECURITY IN BRAZIL}

\begin{abstract}
The article presents an interpretation of the evolution of the debate on food security in Brazil. The ambiguities that characterize food security concepts are taken as a starting point to explain the emergence of the notion of food sovereignty. In the Brazilian case, the integration of this notion of sovereignty in the construction of meanings of food and nutritional security marks the claims of the social movement and public initiatives in this area.
\end{abstract}

Keywords: Food Security, Food Sovereignty, Agri-Food Public Policies, Family Farming, Right to Healthy Food.

\section{LA INTEGRACIÓN DE LA NOCIÓN DE SOBERANÍA EN LA CONCEPCIÓN PREDOMINANTE DE LA SEGURIDAD ALIMENTARIA Y NUTRICIONAL EN BRASIL}

\section{RESUMEN}

El artículo presenta una interpretación de la evolución del debate en torno a la noción de seguridad alimentaria y nutricional en Brasil. Las ambigüedades que caracterizan los conceptos de seguridad alimentaria se toman como punto de partida para explicar el surgimiento de la noción de soberanía alimentaria. En el caso brasileño, la integración de esta última en la construcción de significados de seguridad alimentaria y nutricional marca las demandas del movimiento social y las iniciativas públicas en esta área.

Palabras clave: Seguridad Alimentaria, Soberanía Alimentaria, Políticas Públicas Agroalimentarias, Agricultura Familiar, Derecho Humano a una Alimentación Saludable.

\footnotetext{
${ }^{1}$ Docente do Programa de Pós-Graduação Interunidades (CENA-ESALQ) em Ecologia Aplicada da Universidade de São Paulo. E-mail pmarques@usp.br.

${ }^{2}$ Nutricionista e Mestre em Ecologia Aplicada pela Universidade de São Paulo. E-mail: nataliagebrimdoria@gmail.com.
} 


\section{INTRODUÇÃO}

Este artigo tem como objetivo veicular interpretações sobre a evolução do debate sobre a segurança alimentar, considerando as particularidades deste processo no Brasil. A intenção consiste em revisitar artigo publicado na revista SAN/NEPA/UNICAMP (Moruzzi Marques, 2010), no qual são destacadas as ambiguidades nas conceituações de segurança alimentar, o que constitui uma base consistente para explicar a emergência da noção de soberania alimentar. Estas interpretações são construídas a partir de resultados de investigações realizadas desde meados dos anos 1990. A pesquisa contou notadamente com análises documentais (Doria, 2019).

Desta maneira, foi possível evidenciar que, por diferentes razões explicitadas ao longo da explanação, não ocorre, no caso do Brasil, uma polarização entre as duas noções focalizadas aqui. Com efeito, a proposta de soberania tem sido mobilizada de modo a integrar a noção de segurança alimentar e nutricional (SAN), permitindo definir precisamente seus sentidos com uma perspectiva favorável à agricultura camponesa, tal como concebido originalmente pela Via Campesina.

Com esta linha de raciocínio, este artigo é elaborado em três partes. Em primeiro lugar, tratase de apresentar o nascimento e controvérsias em torno da noção de segurança alimentar, explorando elementos da abordagem cognitiva das políticas públicas. Em seguida, são discutidas as particularidades do debate brasileiro sobre o tema. Enfim, a última parte do texto focaliza evidências da incorporação da noção de soberania alimentar em legislações e programas destinados à promoção de segurança alimentar e nutricional, bem como destaca o quadro atual de desmonte de políticas visando assegurar o direito humano à alimentação saudável.

\section{POLISSEMIA EM TORNO DA NOÇÃO DE SEGURANÇA ALIMENTAR SOB UMA ÓTICA DA ABORDAGEM COGNITIVA DAS POLÍTICAS PÚBLICAS}

A noção de segurança alimentar nasce associada à nomenclatura militar, na perspectiva de defesa nacional, já na primeira guerra mundial. Nesta ótica, a disponibilidade de alimento é considerada como essencial em caso de conflitos armados entre nações. No fim da segunda grande guerra, a noção ganha muita difusão, especialmente com o advento da Organização das Nações Unidas (ONU), em 1945. Em suas primeiras formulações, a segurança alimentar apresenta caráter ao mesmo tempo produtivista e protecionista. Tratava-se de assegurar oferta alimentar abundante, com apoio à intensificação da produção agrícola nacional. Os propósitos da chamada Revolução Verde reforçam esta orientação.

Na perspectiva da abordagem cognitiva das políticas públicas, é um referencial modernizador que orienta a ação visando a adaptação do setor agrícola para o alcance da segurança alimentar. Ou seja, a partir da identificação de um problema segundo o qual a agricultura estava à margem das 
mudanças econômicas, pois considerada como arcaica, a modernização seria a solução para permitir integrar as unidades de produção agrícola ao mercado. Mesmo que esta escolha pudesse implicar forte o êxodo rural, as políticas públicas de modernização da agricultura foram vistas como imprescindíveis, exigindo aumento do tamanho dos estabelecimentos para alcance da eficácia técnica desejada. Além de responder ao problema identificado, o ajustamento setorial modernizador promoveu uma nova relação dos agricultores com a sociedade global, implicando forte adesão aos propósitos modernizadores por parte das organizações que os representavam (Muller, 2003).

Este quadro é representado pelo caso da Comunidade Econômica Europeia, bastante elucidativo desta perspectiva de ação do Estado em prol da segurança alimentar. Pilar da estruturação do projeto de integração europeia, a Política Agrícola Comum (PAC) visou assegurar, com o objetivo de alcance de segurança alimentar, o abastecimento dos mercados europeus de alimentos com uma considerável sustentação da produção agrícola e com administração de estoques públicos (Squeff, 2016). O acesso individual ao alimento, na perspectiva do direito humano à alimentação, não foi abarcado por esta concepção de segurança alimentar, pois as políticas de bem-estar social, implantadas na época, garantiam um mínimo necessário para poder se alimentar, em contexto de intenso crescimento econômico na Europa. Desta forma, agricultores que se dirigiam para as cidades, em razão de sua exclusão do processo modernizador da agricultura, encontravam rapidamente novas oportunidades de trabalho (Delorme, 2004).

Assim, foi esta modernização agrícola acelerada que permitiu assegurar oferta abundante e barata de alimentos, graças a uma parcela da agricultura familiar que se transformou decisivamente para se tornar muito produtiva. O forte apoio público à modernização, além da preferência por alimentos europeus, foram essenciais para o êxito desta orientação de segurança alimentar, fundada em referencial modernizador que promoveu um produtivismo protecionista (Rémy, 2004).

Gradualmente, o foco no aumento considerável da produção, objetivo efetivamente alcançado, deslocou-se para outras preocupações europeias em relação aos problemas agroalimentares. Cada vez mais, a qualidade sanitária duvidosa dos alimentos e as degradações socioambientais em razão do produtivismo passam a nutrir a crítica crescente contra as escolhas públicas neste âmbito (Bruegel; Staziani, 2004).

De toda forma, essas marcas produtivistas impregnam importantes abordagens de segurança alimentar, mesmo que existam dissonâncias nesse campo entre Organização das Nações Unidas, Banco Mundial, Organização para a Cooperação e Desenvolvimento Econômico (OCDE) e Fundo Monetário Internacional. Nesse contexto, a Cúpula Mundial da Alimentação, realizada em Roma em 1996, apresentou, em seu relatório final, margem para interpretações segundo as quais segurança alimentar se alcança com produção abundante de alimentos muito baratos, o que deveria ser estimulado pela intensificação do comércio internacional. Trata-se de uma orientação para o 
abastecimento alimentar sob lógicas exclusivas de mercado e não propriamente visando assegurar o direito inalienável à alimentação. A origem do produto ou as escolhas produtivas são negligenciadas aqui. Nesta ótica, em nome da segurança alimentar, defende-se uma perspectiva com grande tonalidade liberal produtivista, representando também a pujante emergência do referencial de mercado no último quarto do século passado.

Em oposição a essa perspectiva, a Via Campesina lança, em 1996, sua proposta de soberania alimentar. Nesta concepção, o problema do abastecimento alimentar e do combate à fome seria respondido de maneira muito mais eficaz com apoios às agriculturas camponesas, que poderiam mobilizar de forma sustentável os recursos naturais disponíveis, além de gerar emprego e renda graças a uma atividade agrícola diversificada, adaptada aos ecossistemas e coerente com os hábitos alimentares das populações locais, promovendo autonomia produtiva aos povos e nações.

Efetivamente, a concepção da Via Campesina para abordar os problemas agroalimentares apresenta muita sintonia com as expectativas que nascem com o debate sobre o desenvolvimento sustentável, correspondendo a um referencial progressivamente integrado na concepção da ação pública. A propósito, na Conferência Mundial sobre Desenvolvimento e Meio Ambiente, realizada no Rio de Janeiro, em 1992, a emergência da noção de multifuncionalidade da agricultura estimula uma reflexão das mais fecundas sobre diferentes papéis que a atividade agrícola deveria desempenhar. Trata-se de uma superação da visão anterior sobre as "funções" da agricultura, que limitavam sua contribuição ao suporte do desenvolvimento industrial, com liberação de mão de obra agrícola para as atividades urbano-industriais, com redução dos preços dos alimentos para que as famílias destinem maior proporção de seu orçamento doméstico à aquisição de bens industriais de consumo e, também, com sua grande dependência de insumos e equipamentos industriais (Delgado, 2009).

Sob a ótica da multifuncionalidade da agricultura, que também pode ser concebida como um referencial setorial para a ação pública (Chiodi; Moruzzi Marques, 2018), a contribuição da atividade agropecuária para a sociedade passa a ter outro caráter. Assim, os cuidados com o meio ambiente, a reprodução social das famílias agrícolas em condições dignas, a oferta de alimentos saudáveis e a ocupação equilibrada dos territórios rurais tornam-se centrais nesta construção de ideias sobre as funções da agricultura (Carneiro; Maluf, 2003).

Com efeito, a concepção de soberania alimentar se nutre dessas perspectivas, tornando-se uma noção muito importante na disputa de sentidos atribuídos à sustentabilidade. A propósito, em 2001, ocorreu em Havana, Cuba, o primeiro Fórum Mundial sobre a Soberania Alimentar. Nesta ocasião, foi produzida uma declaração final ${ }^{3}$ na qual notadamente a soberania alimentar é apresentada como

\footnotetext{
${ }^{3}$ Seu conteúdo integral se encontra neste site: https://www.fuhem.es/media/ecosocial/file/Boletin\%20ECOS/ECOS\%20CDV/Bolet $\% C 3 \% A D n \% 204 /$ dec_final_foro.p df
} 
um direito dos povos em reconhecer uma agricultura - com camponeses, indígenas e comunidades pesqueiras - vinculada ao território e prioritariamente orientada para a satisfação dos mercados locais e nacionais, tendo como preocupação central o ser humano. Dessa forma, esta agricultura preserva, valoriza e fomenta a multifuncionalidade dos modos camponeses e indígenas de produção e gestão do território rural.

Em 2007, o Fórum Mundial pela Soberania Alimentar ${ }^{4}$, realizado em Nyéléni, no Mali, definiu mais precisamente as linhas centrais da proposta. Trata-se de um direito dos povos a alimentos nutritivos e culturalmente adequados, acessíveis, produzidos de forma sustentável e ecológica. A noção pressupõe o direito de decidir de cada povo sobre o seu próprio sistema alimentar e produtivo. Assim, aqueles que produzem, distribuem e consomem alimentos devem se situar no coração e no cérebro dos sistemas e políticas alimentares, acima das exigências dos mercados e das empresas. Nesta ótica, a soberania alimentar defende os interesses das gerações atuais e futuras, em consonância com a perspectiva do desenvolvimento sustentável. Políticas fundadas em seu nome representam uma estratégia para resistir ao livre comércio e ao poder das grandes corporações multinacionais agroalimentares. Assim, devem se orientar prioritariamente para a promoção de sistemas alimentares, agrícolas, pastoris e pesqueiros em economias locais, destinando seus produtos aos mercados regionais e nacionais. Sua concepção visa favorecer o empoderamento dos camponeses, incluindo aqui agricultura familiar, pesca artesanal e pastoreio tradicional, o que tornaria a produção, a distribuição e o consumo alimentar uma base para a sustentabilidade em sentido abrangente. Com essas diretrizes, trata-se igualmente de promover comércio transparente, condições de vida dignas para todos os povos e direitos dos consumidores de controlarem a própria alimentação e nutrição. As ações públicas fundadas em soberania alimentar devem ainda garantir direitos de acesso e gestão das terras, territórios, águas, sementes, animais e biodiversidade por aqueles que produzem os alimentos. Enfim, a soberania alimentar supõe novas relações sociais livres de opressão e desigualdades entre homens e mulheres, grupos étnicos, classes sociais e gerações.

\section{O CASO BRASILEIRO}

A discussão em torno da conceituação de segurança alimentar no Brasil se remete frequentemente à obra de Josué de Castro, eminente autor que enfatizou de forma pioneira o tema da fome no Brasil e no mundo. Em seu livro Geografia da Fome, com primeira edição em 1946 (Castro, 2006), o autor considera o tema enquanto um problema de ordem sociopolítica e não de ordem fisiológica, como era tratado até então. Desta maneira, a fome seria resultante do estigma do subdesenvolvimento, com raízes no colonialismo e na formação social herdada da escravidão. Em

\footnotetext{
${ }^{4}$ A Declaração do Fórum de Nyéléni se encontra aqui: https://nyeleni.org/spip.php?article327. 
sua obra, Castro questiona a organização dos sistemas agroalimentares pautados em pujantes interesses econômicos internacionais e não naqueles da saúde pública. Não surpreende assim que Josué de Castro tenha tido seus direitos políticos cassados pela ditadura militar em 1964, avessa a qualquer crítica social, tendo falecido em 1974, no exílio em Paris, onde lecionava na Universidade Paris VIII Vincennes-Saint Denis.

Suas contribuições à agenda política de combate à fome são notáveis, tendo criado e dirigido o Serviço de Alimentação da Previdência Social (SAPS), o qual pode ser considerado como matriz das políticas de alimentação e nutrição no Brasil. Também participou da Comissão Nacional de Alimentação (CNA) e do lançamento da Cartilha da Merenda Escolar, em 1954, quando se inaugura o debate da alimentação escolar, com sua inclusão entre as ações centrais para o combate à fome e à desnutrição (Doria, 2019).

Nos anos da ditadura militar, as políticas de alimentação, marcadas por autoritarismo e por interesses obscuros, estiveram pautadas por programas de suplementação alimentar, amparados e intermediados por organismos internacionais. A criação do Instituto Nacional de Alimentação e Nutrição (INAN), em 1972, com objetivo de elaborar e implementar o Programa Nacional de Alimentação e Nutrição (PRONAN), em princípio orientado por uma perspectiva interdisciplinar integrando ações de produção, distribuição e consumo (inclusive com uma linha de apoio ao pequeno produtor rural), teve esporádicas ações atendendo a suas orientações originais. Predominaram altos investimentos em políticas econômicas e agrícolas que promoveram concentração de renda e da propriedade da terra, sem liberação de recursos financeiros suficientes para a consolidação do PRONAN. Esse quadro demonstra a ausência de prioridade para o tema alimentar na agenda política brasileira da época (Arruda; Almeida, 2005; Pinheiro, 2008).

Com o fim da ditadura militar e com a transição democrática, um ambiente propício se desenvolveu para a discussão referente à garantia dos direitos básicos e universais, o que levou ao avanço da noção de segurança alimentar no debate público brasileiro. O tema foi ponto de pauta na I Conferência Nacional de Alimentação e Nutrição, ocorrida em 1986, como desdobramento da VIII Conferência Nacional de Saúde, evidenciando o estreitamento da relação entre SAN e saúde, o que abriu perspectivas para a inserção do direito à alimentação nos marcos legais das políticas sociais brasileiras.

$\mathrm{Na}$ ocasião, as questões de SAN foram amplamente debatidas, tendo sido proposta a criação de um Conselho Nacional de Alimentação e Nutrição, que formularia a política nacional neste âmbito, o que foi apenas implementado pelo Ministério da Saúde em 1999. A proposta de um Sistema Nacional de Segurança Alimentar e Nutricional foi também lançada, o que será apenas retomado na II Conferência Nacional de SAN, em 2004 (Burlandy, 2009). 
Portanto, as recomendações da conferência de 1986 não foram implementadas imediatamente, tendo as ações públicas em nome da SAN um caráter muito limitado nesse momento. Todavia, um cenário favorável se desenhava, com o crescimento de movimentos sociais pela democracia e com a instalação da Assembleia Constituinte, responsável pela elaboração da Constituição Federal de 1988. Ainda assim, esta última não incluiu em seu bojo o tema da SAN, com exceção ao que se refere à alimentação escolar.

Com o governo de Fernando Collor de Mello, ocorre notável enfraquecimento da ação pública nesse âmbito, com importantes retrocessos no próprio Programa Nacional de Alimentação Escolar, no Programa de Alimentação do Trabalhador e no Instituto Nacional de Alimentação e Nutrição (INAN). Ademais, foi extinto o dispositivo de suplementação alimentar dirigida a crianças menores de sete anos (Jaccoud; Hadjab; Chaibub, 2009).

É a oposição ao presidente Collor de Mello, reunida no que é conhecido como "governo paralelo", que produz o documento com maior repercussão nesse período, propondo uma Política Nacional de Segurança Alimentar. Esta proposta oposicionista foi abraçada por Itamar Franco, ao assumir a presidência da República com a deposição de Collor de Mello. Desta forma, o combate à fome e à miséria torna-se uma prioridade em seu governo. Em 1993, o Movimento pela Ética na Política, que encabeçou as manifestações pelo impeachment de Fernando Collor de Mello, deu origem à Ação da Cidadania Contra a Fome, a Miséria e pela Vida, liderada pelo sociólogo Herbert José de Souza, o Betinho. Essa evolução foi fundamental para a instituição do Conselho Nacional de Segurança Alimentar (CONSEA), no mesmo ano. Nesse contexto, é formulado o "Plano de Combate à Fome e à Miséria", pactuado entre o governo (incluindo o INAN) e a sociedade civil, no âmbito do recém criado CONSEA. O plano previa a implementação de diversos programas setoriais de forma interdependente, conjunta e coordenada (Pinheiro, 2008). Efetivamente, a constituição do CONSEA inaugura uma perspectiva democrática de fortalecer a participação de atores da sociedade civil em processos de discussão e tomada de decisão no âmbito do Estado, no que se refere às questões agroalimentares.

Convém destacar aqui o papel da Ação da Cidadania, com muita capilaridade graças à instalação de comitês locais por todo o país. Seus membros tiveram notadamente grande participação na organização da primeira Conferência Nacional de Segurança Alimentar (I CNSA), ocorrida em 1994, reunindo cerca de 2000 delegados de todos os estados do Brasil. A contribuição da I CNSA se refere particularmente à consolidação da implementação da Política Nacional de Alimentação e Nutrição (Pinheiro, 2008; Burlandy, 2009), mencionada anteriormente.

Essa trajetória do debate reforçou a adoção de uma perspectiva de segurança alimentar associada à democratização substancial da sociedade brasileira. Em primeiro lugar, a construção da noção cumpriu um importante papel de estímulo a uma forte mobilização social. Com esta orientação, 
o acesso a uma alimentação adequada, princípio essencial de segurança alimentar e nutricional, deveria ser acompanhado pela promoção de todos os direitos sociais, tal como pode ser considerado a partir dos temas que foram tratados na I CNSA, a saber: questão agrária; desenvolvimento rural; política agrícola; abastecimento alimentar; desenvolvimento; assistência social; saúde; educação; geração de emprego e renda; participação popular e democracia.

Nessa primeira metade da década de 1990, a realização da Conferência das Nações Unidas sobre Meio-Ambiente e Desenvolvimento, mencionada anteriormente, favorece posições contestadoras às dinâmicas produtivistas e às lógicas socioeconômicas do capitalismo. Esta visão crítica enfrentou (e enfrenta) uma forte concorrência com posturas orientadas pelo programa neoliberal, difundido como Consenso de Washington (Santos, 2019), muito pujante na década em questão.

De todo modo, é evidente que a noção de soberania alimentar integra princípios emergentes de justiça ecológica (Van Dam; Nizet, 2012; Retière; Moruzzi Marques, 2019), impulsionados especialmente pelo debate sobre o desenvolvimento sustentável, tal como sugerido acima. No campo de produção de ideias em torno da soberania alimentar, são muito representativas as mudanças no Movimento dos Trabalhadores Rurais Sem Terra (MST), em razão notadamente de sua adesão à Via Campesina, correspondendo a uma reorientação estratégica agroecológica. Com efeito, a concepção contraditória do MST nos anos 1980-90 de modelo produtivista para os assentamentos (na medida em que os assentados se tornam muito dependentes de insumos industriais e de financiamento agropecuário) foi gradualmente substituída pela defesa da agroecologia (Borsatto; Carmo, 2013), com repercussões das mais originais nos níveis locais (Moruzzi Marques; Gaspari; Almeida, 2017).

Abrigando perspectivas distintas ${ }^{5}$, a primeira experiência do Conselho Nacional de Segurança Alimentar foi de curta duração. Em 1995, o governo de Fernando Henrique Cardoso o substituiu pelo Conselho da "Comunidade Solidária", programa que representou uma perspectiva neoliberal de tratamento dos problemas sociais (Moruzzi Marques, 2003).

Nessas circunstâncias, como resultado da mobilização da sociedade civil na preparação e participação do Brasil na Cúpula Mundial da Alimentação (1996), nasce, em 1998, o Fórum Brasileiro de Segurança Alimentar e Nutricional (FBSAN), que mais tarde incorpora o termo "soberania" em sua denominação. Com a desativação do CONSEA, o FBSAN cumpriu fundamental papel de manter viva a articulação social em torno da temática da segurança alimentar e nutricional e do direito humano à alimentação adequada. Sua existência constituiu um fator importante para a reinstalação

\footnotetext{
5 Convém destacar que uma perspectiva produtivista de segurança alimentar emerge no Brasil neste momento, tendo representação no CONSEA (Pompeia; Schneider, 2021). Em seu nascimento, a Associação Brasileira de Agribusiness (ABAG) lança, como seu primeiro manifesto, uma proposta de segurança alimentar, fundada na ideia de que a estabilidade política e econômica permitiria que o setor agroindustrial brasileiro pudesse investir para o aumento da oferta de alimentos, o que seria o principal meio para se alcançar segurança alimentar (Moruzzi Marques, 2010).
} 
do CONSEA, em 2003, enquanto catalisador da participação da sociedade civil tanto no conselho nacional, quanto nos conselhos estaduais e na preparação das conferências de SAN. Além desse papel, o FBSAN é o principal elo entre a sociedade civil brasileira e aquela internacional nas temáticas em questão (Burity et al., 2009).

\section{A REINSTALAÇÃO DO CONSEA E A INTEGRAÇÃO DO SENTIDO DE SOBERANIA NA ORIENTAÇÃO DE SEGURANÇA ALIMENTAR E NUTRICIONAL}

Em 2003, o lançamento da iniciativa governamental Fome Zero, visando articulação interministerial de ações de curto, médio e longo prazo, voltadas à garantia da segurança alimentar e nutricional e ao combate à pobreza, representou novo patamar na trajetória da noção em questão. Desta forma, ocorrem importantes mudanças nos marcos institucionais e legais, com a reinstalação em 2003 do Conselho Nacional de Segurança Alimentar e Nutricional (CONSEA), como órgão de assessoramento do presidente da República, e com a criação do Ministério Extraordinário de Segurança Alimentar e Combate à Fome (MESA). As circunstâncias políticas favoráveis associadas à eleição de Luiz Inácio Lula da Silva para presidente da República foram reforçadas graças à relevante mobilização do FBSAN, que manteve em evidência a pauta da SAN a partir de intensa articulação da sociedade civil organizada.

O CONSEA representa um importante significado de democratização e de participação social na tomada de decisões no campo agroalimentar. Como proposta da II Conferência Nacional de Segurança Alimentar e Nutricional, em março de 2004, o Conselho se estrutura com $2 / 3$ de seus membros oriundos da sociedade civil e $1 / 3$ do poder público. Sua mesa diretora é composta exclusivamente por membros da sociedade civil. Essa estrutura sinaliza para uma importante abertura do espaço institucional para a participação de diferentes grupos sociais interessados no balizamento das políticas públicas de segurança alimentar e nutricional. Efetivamente, essa participação foi significativa para a implementação de marcos legais que promoveram a melhora nos índices de insegurança alimentar, permitindo ao Brasil sair do "Mapa da Fome" das Nações Unidas, em 2014. A propósito, o índice de insegurança alimentar e nutricional grave ${ }^{6}$ passou de 6,9\% da população, em 2004, para 3,2\% em 2013, segundo a Pesquisa Nacional de Amostra por Domicílio (IBGE, 2014).

Com a nova configuração institucional, as iniciativas no âmbito das compras públicas evidenciam bastante uma fundamentação ancorada em referencial de soberania alimentar. Assim, é instituída, graças ao artigo 19 da Lei $\mathrm{n}^{\mathrm{o}}$ 10.696, de 2003, uma proposta inovadora e pioneira, o

\footnotetext{
${ }^{6} \mathrm{Na}$ insegurança alimentar grave, há redução severa no consumo de alimentos entre adultos e crianças, rompendo desse modo os padrões alimentares e resultando em carência alimentar entre todos os moradores do domicílio, o que é equiparado a uma situação de fome.
} 
Programa de Aquisição de Alimentos (PAA) ${ }^{7}$, que promove a abertura do mercado institucional para produtos da agricultura familiar, através de compras públicas, dispensando o processo licitatório, que é substituído pelas chamadas públicas. Desta maneira, ocorre significativa simplificação do processo de aquisição pública, contornando uma barreira importante para que a agricultura familiar possa acessar aos mercados institucionais (Schmitt, 2005). As normas do PAA prescrevem ainda que os preços de aquisição não podem ser superiores àqueles praticados nos mercados regionais e também estabelece que os produtos agroecológicos ou orgânicos podem ter um acréscimo de até 30\% (trinta por cento) em relação aos preços dos alimentos convencionais (Lei no 12.512 de 2011). Com esta característica, o programa visa a distribuição de gêneros alimentícios para pessoas em situação de insegurança alimentar e a formação de estoques estratégicos, integrando ações de combate à fome e promoção da segurança alimentar e nutricional.

Esse modelo de compra pública inspirou uma mudança significativa no Programa Nacional de Alimentação Escolar, com a aprovação da Lei no 11.947, em 16 de junho de 2009. Trata-se de tornar obrigatória a utilização de, no mínimo, 30\% dos recursos financeiros repassados pelo Fundo Nacional de Desenvolvimento da Educação (FNDE) às entidades executoras (estados e prefeituras) para a aquisição de produtos da agricultura familiar, com prioridade para assentamentos de reforma agrária, comunidades tradicionais indígenas e quilombolas. Aliás, a integração de mais produtos in natura na alimentação escolar, com o apoio ao produtor rural local, já era discutida desde 1976, no âmbito da elaboração do PRONAN II. No entanto, não se concretizaram naquele período ações efetivas neste sentido (Doria, 2019).

Como sugere Sandro Pereira Silva (2014), a concepção destes dispositivos de SAN (PAA e PNAE) é orientada por um referencial sustentável emergente de políticas públicas (Muller, 2003, 2010; Massardier, 2010), combinando elementos de multifuncionalidade da agricultura, circuitos curtos de proximidade e, especialmente, soberania alimentar (Darrot; Durant, 2010; Grisa; Schneider, 2014; Moruzzi Marques; Moal, 2014; Chiodi; Moruzzi Marques, 2018).

Com efeito, a trajetória do debate sobre a SAN no Brasil reflete efetivamente sua associação estreita com a defesa da democratização, da agricultura familiar, da agroecologia e do direito à alimentação e nutrição adequadas e saudáveis. No entanto, não se deve ignorar que, no mesmo período, também houve avanço de agendas favoráveis à expansão do agronegócio e das transnacionais da alimentação, atendendo interesses de grandes proprietários fundiários e dos conglomerados agroalimentares industriais (Burity et al., 2017).

\footnotetext{
7 A orientação do PAA apoiada na noção de soberania alimentar foi realçada por Regina Aparecida Leite de Camargo, José Giacomo Baccarin e Denise Boito Pereira da Silva (2016), em estudo sobre as relações entre mercados institucionais e assentamentos no norte do estado de São Paulo.
} 
Esta contradição quanto ao modelo de desenvolvimento rural promovido pelo Estado brasileiro se refletia na estruturação de dois ministérios paralelos, implicando bloqueios importantes para a perspectiva de soberania alimentar. Por um lado, o Ministério do Desenvolvimento Agrário (MDA), extinto em 2016, era responsável pelas políticas voltadas ao fortalecimento da agricultura familiar e à promoção da reforma agrária. Por outro lado, o Ministério da Agricultura, Pecuária e Abastecimento (MAPA) atende os interesses do agronegócio exportador e da agricultura patronal em larga escala.

Seja como for, o referencial de soberania alimentar sustentou em grande medida a concepção da Lei Orgânica de Segurança Alimentar e Nutricional ${ }^{8}$ (LOSAN), n $^{\circ}$ 11.346/2006, que estabelece o Sistema Nacional de Segurança Alimentar e Nutricional (SISAN) com vistas a assegurar o direito humano à alimentação adequada. Particularmente, seu artigo quinto menciona que "a consecução do direito humano à alimentação adequada e da segurança alimentar e nutricional requer o respeito à soberania, que confere aos países a primazia de suas decisões sobre a produção e o consumo de alimentos".

A homologação da LOSAN e a criação do SISAN são efetivamente resultados da participação social em torno do tema, especialmente na II Conferência Nacional de Segurança Alimentar e Nutricional (II CNSAN), em 2004, que lança tais propostas como prioritárias. Ambas são aprovadas na plenária final da conferência.

Ainda mais, é nesta mesma II CNSAN que se reafirma a óptica de que a SAN deve ter como objetivo estratégico e permanente sua associação com a soberania alimentar. Da mesma forma, é considerada urgente a inclusão da alimentação enquanto direito social reconhecido na Constituição Federal (o que se concretiza em 20109).

Com essas orientações, a estrutura proposta do SISAN se funda em abordagem sistêmica, sob princípios de participação social, de intersetorialidade e de descentralização das ações em regime de colaboração entre as esferas de governo. O sistema em questão é integrado pelo CONSEA, por suas conferências nos níveis federal, estaduais e municipais, pela Câmara Intersetorial de Segurança Alimentar e Nutricional (CAISAN) e, enfim, por órgãos, entidades e instituições privadas sem fins lucrativos, vinculados ao tema.

Outros eventos relevantes que merecem menção aqui se referem à realização de novas CNSAN (cinco edições até 2015); à instituição da Política Nacional de SAN, através do Decreto $n^{\circ}$ 7.272/2010 de regulamentação da LOSAN; à publicação do I Plano Nacional de SAN (PLANSAN),

\footnotetext{
${ }^{8}$ A definição de segurança alimentar e nutricional nesta lei diz respeito à "realização do direito de todos ao acesso regular e permanente a alimentos de qualidade, em quantidade suficiente, sem comprometer o acesso a outras necessidades essenciais, tendo como base práticas alimentares promotoras de saúde que respeitem a diversidade cultural e que sejam ambiental, cultural, econômica e socialmente sustentáveis".

9 A Emenda Constitucional n ${ }^{\mathrm{o}} 64$, de 2010, altera o artigo $6^{\circ}$ da Constituição Federal para introduzir a alimentação como um direito social.
} 
em 2011, com vigência de 2012 a 2015, e do II PLANSAN (2016/2019), elaborado pela CAISAN e pelo CONSEA a partir das diretrizes da V CNSAN.

Não por acaso, o conceito de SAN adotado pelo Brasil - em ambiente favorável para o avanço de sua perspectiva democrática e soberana em razão da abertura para a participação social - torna-se internacionalmente reconhecido como uma noção inovadora no campo das políticas públicas afirmativas do direito humano à alimentação adequada. Trata-se de uma combinação de três conceituações de forma complementar e não excludente: segurança alimentar e nutricional; direito humano à alimentação adequada e soberania alimentar.

\section{AS AMEAÇAS ÀS POLÍTICAS DE SEGURANÇA ALIMENTAR E NUTRICIONAL DESDE O GOLPE DE 2016}

Conforme a cronologia concebida por Conti (2016), a trajetória da SAN no Brasil poderia ser dividida em três períodos, caracterizados da seguinte forma: (1) abastecimento e assistência alimentar (1920-1980); (2) ação da cidadania contra a fome e pela SAN (1980-2002); (3) construção participativa de políticas públicas de SAN (2003-2015). A partir de 2016, após o impeachment da presidenta Dilma Rousseff, é pertinente propor um novo período desta trajetória, marcado pelo desmonte das políticas de SAN e pelo cerceamento da participação social em sua construção.

Com a posse de Michel Temer, após o golpe de 2016 que derrubou o governo de Dilma Rouseff (Miguel, 2016), uma série de medidas fragilizou a institucionalidade dos programas de segurança alimentar e nutricional. Convém destacar aqui o enfraquecimento do $\mathrm{PAA}^{10}$, com uma drástica diminuição de seu orçamento. Ademais, a extinção do Ministério do Desenvolvimento Agrário significou o desaparecimento de um espaço estratégico na disputa das políticas de desenvolvimento rural e de cunho agroalimentar, deixando livre o caminho para a hegemonia dos grupos sociais identificados com o agronegócio, como os representantes da grande agricultura ou da indústria de agrotóxicos (Santarelli; Burity, 2017). Neste quadro, são evidentes as ameaças ao apoio público à agricultura familiar e os bloqueios para perspectivas de soberania alimentar.

Os retrocessos são bem representados pela Emenda Constitucional $n^{\circ} 95$, de dezembro de 2016, conhecida como PEC do teto dos gastos públicos, que limita o crescimento das despesas, especialmente em educação e saúde, do governo brasileiro, durante 20 anos, alcançando os três poderes, Ministério Público e Defensoria Pública da União. Trata-se de uma medida de caráter

\footnotetext{
${ }^{10}$ A propósito, a Medida Provisória 1.061, de agosto de 2021, extingue o Programa de Aquisição de Alimentos (PAA) e o substitui pelo Programa Alimenta Brasil, o que implica incertezas quanto ao aporte de recursos e exigências de um novo modelo de governança e de regulamentação. Assim, é plausível esperar entraves para a execução do novo programa e prejuízos ao público já atendido pelo PAA, associados à extinção de modalidades existentes de ação pública pertinente neste âmbito.
} 
claramente neoliberal, que significa desengajamento do Estado diante do objetivo de garantir direitos constitucionais conquistados pelos segmentos mais marginalizados da sociedade brasileira.

A partir de 2019, multiplicam-se as ameaças e violações aos direitos sociais e humanos com a posse, como presidente da República, de Jair Bolsonaro. Já como ato inaugural, seu governo publica a Medida Provisória $n^{\circ} 870$, que extingue o CONSEA. Este último ainda foi reativado em maio do mesmo ano pelo Congresso Nacional, inserindo-o no Ministério da Cidadania e assim deixando de ser órgão de assessoramento da Presidência da República. No mês seguinte, um veto presidencial revoga, todavia, a decisão parlamentar com a justificativa de "invasão de prerrogativas" do executivo pelo legislativo. Por fim, o veto foi acolhido pelo Congresso Nacional, em 24 de setembro, confirmando a supressão do CONSEA. Trata-se de demonstração nítida da aversão por instrumentos democráticos conquistados pela sociedade civil organizada no Brasil, o que é contrário às diretrizes pactuadas na Constituição Federal (Castro, 2019; Doria, 2019). Com efeito, a extinção do CONSEA representa a desestruturação do Sistema Nacional de Segurança Alimentar e Nutricional e o bloqueio à participação social, deflagrando um processo de degradação do tratamento do tema e sua marginalização na agenda pública, o que implica grave ameaça ao direito humano à alimentação e nutrição adequadas.

Não por acaso, os indicadores de insegurança alimentar grave apresentam uma piora acentuada no acesso à alimentação por parte das famílias brasileiras, o que se reflete no vertiginoso aumento no quadro de insegurança alimentar da população brasileira. Estudo realizado pela Rede Brasileira de Pesquisa em Soberania e Segurança Alimentar e Nutricional, em 2020, revelou que $55,2 \%$ dos brasileiros conhecem algum grau de insegurança alimentar ${ }^{11}$, dos quais $9 \%$ encontram-se em nível grave, o que equivale à fome. Este quadro, agravado pela pandemia de Covid-19, associase ao desmonte das políticas públicas de combate à fome e de garantia da segurança alimentar e nutricional, refletindo-se no retorno do Brasil a um cenário de acentuada vulnerabilidade de grande parte de sua população (Rede Penssan, 2021).

\section{CONCLUSÕES}

No Brasil, a construção da noção de segurança alimentar e nutricional, incorporando os propósitos do Direito Humano à Alimentação e à Nutrição Adequadas (DHANA) e da soberania alimentar, reflete a histórica e intensa participação das organizações populares da sociedade civil neste debate. Apesar de concorrências acirradas, estas últimas conseguiram imprimir um viés democrático e agroecológico nos significados predominantes de SAN.

\footnotetext{
11 Os níveis dessa classificação foram obtidos através da Escala Brasileira de Insegurança Alimentar (EBIA), apresentando a seguinte estratificação: Segurança Alimentar; Insegurança Alimentar Leve; Insegurança Alimentar Moderada; Insegurança Alimentar Grave.
} 
Deste modo, o Brasil apresentou avanços significativos na concepção de políticas e implantação de dispositivos públicos fundados em referencial de soberania alimentar para o alcance do DHANA. Intensa participação marca estes processos que, mesmo apresentando contradições, favoreceram o reconhecimento do fundamental papel alimentar da agricultura familiar e o intenso debate sobre uma alimentação saudável.

O desmonte institucional em curso desde 2016 revela que os esforços realizados ao longo do período anterior não bastaram para assegurar a consolidação de ações consistentes em favor da SAN e do DHANA. Todavia, estados e municípios permanecem com forte atuação neste âmbito, com muitos conselhos locais, contando com a participação da sociedade civil, engajados na construção de iniciativas públicas agroalimentares pertinentes. O FBSSAN segue desempenhando papel essencial na mobilização social pela pauta da segurança alimentar e nutricional, com clara orientação pela soberania, coordenando a articulação nacional em torno do tema. Portanto, esta base local e descentralizada oferece uma promissora perspectiva para a reconstrução no nível federal dos dispositivos com vistas a garantir o direito humano à alimentação e nutrição adequadas.

\section{REFERÊNCIAS}

ARRUDA, E. E.; ALMEIDA, C. M. A mercantilização do Programa Nacional de Merenda Escolar. Intermeio: Revista do Mestrado em Educação, 11(22), 2005, p. 88-110.

BORSATTO, R.; CARMO, M. S. A construção do discurso agroecológico no Movimento dos Trabalhadores Rurais Sem-Terra (MST). Revista de Economia e Sociologia Rural, 51(4), 2013, p. 645-660.

BRUEGEL, M.; STANZIANI, A. Pour une histoire de la sécurité alimentaire. Revue d'histoire moderne \& contemporaine, v. 51, n. 3, 2004, p. 7-16.

BURLANDY, L. A construção da política de segurança alimentar e nutricional no Brasil: estratégias e desafios para a promoção da intersetorialidade no âmbito federal de governo. Revista Ciência \& Saúde Coletiva, v. 14, n. 3, 2009, p. 851-860.

BURITY, V.; FRANCESCHINI, T.; VALENTE, F.; RECINE, E.; LEÃO, M.; CARVALHO, M. F. Direito humano à alimentação adequada no contexto da segurança alimentar e nutricional. Brasília/DF: ABRANDH, 2010.

CAMARGO, R. A. L.; BACCARIN, J. G.; SILVA, D. B. P.. Mercados institucionais para a agricultura familiar e soberania alimentar. Revista NERA, n. 32, 2016, pp. 34-55.

CARNEIRO, M. J.; MALUF, R. Para além da produção: multifuncionalidade e agricultura familiar. Rio de Janeiro: Mauad, 2003.

CASTRO, J. Geografia da Fome. Primeira edição 1946. Rio de Janeiro: Editora Civilização Brasileira, 2006.

CASTRO, I. R. R. A extinção do Conselho Nacional de Segurança Alimentar e Nutricional e a agenda de alimentação e nutrição. Cadernos de Saúde Pública, v. 35, n. 2, 2019, p. 1-4. 
CHIODI, R.; MORUZZI MARQUES, P. E. Multifuncionalidade da Agricultura e Serviços ambientais: aproximações e distanciamentos como referenciais de políticas públicas. Desenvolvimento em Questão, v. 16, n. 45, 2018, p. 214-232.

CONTI, I. L. Organizações sociais e políticas públicas: inserção da Fetraf-Sul nas políticas públicas de segurança alimentar e nutricional. Tese (Doutorado em Desenvolvimento Rural) - Programa de Pós-Graduação em Desenvolvimento Rural, Universidade Federal do Rio Grande do Sul, PGDR/UFRGS, Porto Alegre, 2016.

DARROT, C.; DURANT, G. Référentiel central des circuits courts de proximité: mise en évidence et statut pour l'action. In: TRAVERSAC, Jean-Baptiste. Circuits courts: contribution au développement régional. Dijon: Educagri éditions 2010.

DELGADO, G. C. Questão Agrária no Brasil: 1950-2003. In: Luciana Jaccoud (Org.), Questão Social e Políticas Sociais no Brasil Contemporâneo, Brasília/DF: IPEA, 2009.

DELORME, H. La Politique Agricole Commune: anatomie d'une transformation. Paris: Presse de Science Po, 2004.

DORIA, N. G. Agricultura familiar e promoção da saúde: um novo olhar para o Programa Nacional de Alimentação Escolar (PNAE). Dissertação (Mestrado em Ecologia Aplicada) - Programa de PósGraduação em Ecologia Aplicada Interunidades (Escola Superior de Agricultura "Luiz de Queiroz" e Centro de Energia Nuclear na Agricultura), Universidade de São Paulo, Piracicaba, 2019.

GRISA, C.; SCHNEIDER, S. Três gerações de políticas públicas para a agricultura familiar e formas de interação entre sociedade e estado no Brasil. Revista de Economia e Sociologia Rural, v. 52 (supl. 1), 2014, p. 125-146.

IBGE. Pesquisa Nacional por Amostra de Domicílios (PNAD). Rio de Janeiro: IBGE, 2014.

JACCOUD, L.; HADJAB, P. D. M.; CHAIBUB, J. R. Assistência social e segurança alimentar: entre novas trajetórias, velha agendas e recentes desafios (1988-2008). Politicas Sociais: acompanhamento e análise - vinte anos da Constituição Federal. Brasília/DF: IPEA, 2009.

MASSARDIER, G. Cognição, políticas e ações públicas: entre coerência, fragmentação e aprendizados. BONNAL, P.; LEITE, S. P. Análise comparada de políticas agrícolas. Rio de Janeiro: Mauad X e CIRAD, 2011.

MIGUEL, L. F. O colapso da democracia no Brasil: da Constituição ao golpe de 2016. São Paulo: Fundação Rosa Luxemburgo e Expressão Popular, 2019.

MORUZZI MARQUES, P. E. Concepções em disputa na formulação das políticas públicas de apoio à agricultura familiar: uma releitura sobre a criação do PRONAF. Raízes, v. 22, n. 2, 2003, p. 16-28.

MORUZZI MARQUES, P. E. Embates em torno da segurança e soberania alimentar: estudo de perspectivas concorrentes. Revista Segurança Alimentar e Nutricional, v. 17, n. 2, 2010, p. 78-87.

MORUZZI MARQUES, P. E.; MOAL, M. Programme d'Acquisition d'Aliments (PAA) au Brésil : l'agriculture locale et familiale au cœur de l'action publique en vue de la sécurité alimentaire. VertigO: la revue électronique en sciences de l'environnement. v. 14, 2014, p. 1-18.

MORUZZI MARQUES, P. E.; GASPARI, L. C.; ALMEIDA, B. Organização de Controle Social (OCS) e engajamento agroecológico das famílias do assentamento Milton Santos no estado de São Paulo. Estudos Sociedade e Agricultura, 25(3), 2017, p. 545-560.

MULLER, Pierre. Les politiques publiques. Paris: PUF, 2003.

MULLER, Pierre. Introduction: les changements d'échelles des politiques agricoles. Le monde agricole en politique: de la fin des paysans au retour de la question agricole. Paris: Presse de Science Po, 2010, p. 339-350. 
PINHEIRO, A. R. O. Reflexões sobre o Processo Histórico / Político de Construção da Lei Orgânica de Segurança Alimentar e Nutricional. Revista Segurança Alimentar e Nutricional, v. 15, n. 2, 2008, p. 1-15.

POMPEIA, C.; SCHNEIDER, S. As diferentes narrativas alimentares do agronegócio. Desenvolvimento e Meio Ambiente, vol. 57, 2021, p. 175-189

REDE PENSSAN. Insegurança alimentar e Covid-19 no Brasil: VIGISAN, Inquérito Nacional sobre Insegurança Alimentar no Contexto da Pandemia da Covid-19 no Brasil. 2021. Disponível em: $<$ http://olheparaafome.com.br/VIGISAN_Inseguranca_alimentar.pdf $>$. Acesso em: 27 nov. 2021.

RÉMY, J. Um caminho sinuoso e semeado de espinhos. Os agricultores franceses: da especialização e intensificação da produção à multifuncionalidade e ao desenvolvimento sustentável. Estudos Sociedade e Agricultura, v. 12, n. 1, 2005, p. 5-50.

RETIERE, M.; MORUZZI MARQUES, P. E. A justiça ecológica em processos de reconfiguração do rural: estudo de caso de neorrurais no estado de São Paulo. Revista de Economia e Sociologia Rural, v. 57, n. 3, 2019, 490-503.

SANTARELLI, M.; BURITY, V.; SILVA, L. N. B.; PRATES, L.; RIZZOLO, A.; ROCHA, N. C.; TRABUCO, L. Da democratização ao golpe: avanços e retrocessos na garantia do direito humano à alimentação e à nutrição adequadas no Brasil. Brasília: FIAN Brasil, 2017.

SANTOS, B. S. Os processos da globalização. Construindo as Epistemologias do Sul: para um pensamento alternativo de alternativas. Volume I. Buenos Aires: Conselho Latino-Americano de Ciências Sociais, 2019.

SCHMITT, C. J. Aquisição de alimentos da agricultura familiar: integração entre política agrícola e segurança alimentar e nutricional. Revista de Política Agrícola, Ano XIV, ${ }^{\circ}$ 2, Brasília: Embrapa/MAPA, 2005, p. 78-88

SILVA, S. P. A trajetória histórica da segurança alimentar e nutricional na agenda política nacional: projetos, descontinuidades e consolidação. Textos para discussão, $\mathrm{n}^{\circ}$ 1953. Brasília: Instituto de Pesquisa Econômica Aplicada (IPEA), 2014.

SQUEFF, T. A. F. R. Cardoso. O desenvolvimento da Política Agrícola Comum da União Europeia. Revista de Direito Internacional, 13(3), 2016, p. 374-389.

VAN DAM, D.; NIZET, J. Les agriculteurs bio deviennent-ils moins bio? In: Van Dam, D., Stassart, P., Nizet, J. \& Streith, M. Agroécologie: entre pratiques et sciences sociales. Dijon: Educagri, 2012. 